\title{
Performance of Maneuver Control System due to Hydrodynamic Coefficient Changes, Case Study: War Ship of SIGMA Class
}

\author{
Agoes A. Masroeri ${ }^{1, a}$, Aulia Siti Aisjah ${ }^{2, b, c, *}$ \\ ${ }^{1}$ Department of Marine Engineering, Institut Teknologi Sepuluh Nopember, Surabaya, Indonesia \\ ${ }^{2}$ Department of Engineering Physics Institut Teknologi Sepuluh Nopember, Surabaya, Indonesia \\ a.masroeri@its.ac.id, b.auliasa@ep.its.ac.idauliasa20@gmail.com c.auliasa20@gmail.com \\ *corresponding author
}

Keywords: The hydrodynamic coefficient, SIGMA class, autopilot, Clark, PID, Zieger Nichols, Stable.

Abstract: The performance of ship maneuvering control system depends on hydrodynamic coefficient. The development of designing SIGMA class is cause of changing in the magnitude of this coefficient. This paper discusses the characteristics of the autopilot control system in various of hydrodynamic coefficients. The coefficient changes occur due to disturbance conditions from the ocean environment, or changes in ship dimensions. The ship's dimensional changes impact on gain of autopilot control system. Clark's regression is used to calculate the hydrodynamics coefficients of ship. The method of design autopilot control systems uses a PID Zieger Nichols. The stability characteristics of system are analyzed in time and frequency domains. The value of hydrodynamics is linear due to change of length of ship, except the moment of inertia heave. The limit of response stability an autopilot system in tolerance of maximum is $110 \%$ of Lpp.

\section{Introduction}

Control systems that have been implemented in various industrial processes, manufacture, vehicles, and others, in initially use of PID control mode. This mode has advantages in response speed, and system stability performances. Determination of control gain value in PID, ie $\mathrm{Kp}, \mathrm{Ki}$ and $\mathrm{Kd}$, in many application use Zieger-Nichols (ZN) method. The advantage of using ZN method is offline and online tuning [1]. This method has also been applied to autopilot systems in several ship types and classes [2].

The ship's maneuvering control system occupies a very important role in modern shipbuilding technology. The design of the maneuver control system requires several stages. One of the stages is the mathematical modeling of maneuver ship dynamics. [3] The ship maneuver model is illustrated as a rigid body in 6 degrees of freedom: Surge, Sway, Heave, Roll, Pitch, and Yaw. There is a nonlinear model that has been proposed by Abkowitz (1964) in the form of maneuver matrix equation. The matrix equation is determined by the surge resistance and the cross-flow drag forces. This 
nonlinear model was developed by Noorbin (1970). Non-linear models are difficult to apply in control systems in the real in full-scale ships. The Abkowitz model is linearized using a second Taylor series. One of the linear models was proposed by Nomoto (1957), in the order of 1'st and 2'nd order [4].

The parameters of the Nomoto in linear model, determined by the magnitude of the ship's hydrodynamic coefficient. This coefficient can be determined experimentally use the Planar - Motion - Mechanism (PMM) system. PMM model results can scale-up to full scale ship using the Froude number similarity. [5]. The second order of Nomoto models was expressed in the Equation 1 below.

$$
\frac{\psi}{\delta_{R}}(s)=\frac{K_{R}\left(1+T_{3} s\right)}{s\left(1+T_{1} s\right)\left(1+T_{2} s\right)}
$$

Where the parameters in (1) above are obtained from the inertial matrix coefficient of $\mathrm{M}$, the damping matrix of $\mathrm{D}$ and the moment-force vector of $\mathrm{b}$, from the following matrix equation [6].

$$
M \dot{v}+N\left(u_{0}\right) v=b \delta_{R}
$$

The coefficienty of matrices $\mathbf{M}$ and $\mathbf{N}$ in equation (2) contain of ship hydrodynamic parameters, ie $\mathbf{m}=$ mass of vessels $Y_{\dot{v}}^{\prime}=$ derivative of force in sway direction to the rate of sway velocity- $\dot{v}, Y_{\dot{r}}^{\prime}=$ derivative of force in yaw direction to the velocity of yawrate $-\dot{r}, N_{\dot{v}}^{\prime}=$ derivative of moment in sway direction to the rate of sway velocity $-\dot{v}, N_{\dot{r}}^{\prime}=$ derivative of moment in yaw direction to the velocity of yawrate $-\dot{r}, Y_{v}^{\prime}=$ derivative of force in sway direction to the sway velocity - v, $Y_{r}^{\prime}=$ derivative of force in yaw direction to the yawrate $-\mathrm{r}, N_{v}^{\prime}=$ derivative of moment in sway direction to the sway velocity $-\mathrm{v}, N_{r}^{\prime}=$ derivative of moment in yaw direction to the yawrate $-\mathrm{r}, x_{G}=$ center of mass.[7]. Clark (1983) was proposed a linear regresion of hydrodynamic parameters as function of ship dimention, ie: length of perpendicular - Lpp, the breadth - B, the height -T, and block of coefficient $-\mathrm{C}_{\mathrm{B}}$.

The variation of the ship's dimension will affect the hydrodynamic coefficient of the ship, and will change the parameter values of $\mathrm{K}_{\mathrm{r}}, \mathrm{T}_{1}, \mathrm{~T}_{2}$, and $\mathrm{T}_{3}$ of the dynamics maneuvering model in equation (1). The effect of changing the parameters of the dynamics model will affect the response of maneuver control system. This paper will describe the results of the ship dimension change analysis on the performance of the control system. The testing was used PID control mode. The tuning of PID parameters using a Zieger Nichols method [8].

\section{Method}

\subsection{Design of Maneuver Control}

The block diagram of maneuver control system is composed of comparataot, controller, and model of ship dynamics. Figure 1 is show the control system.

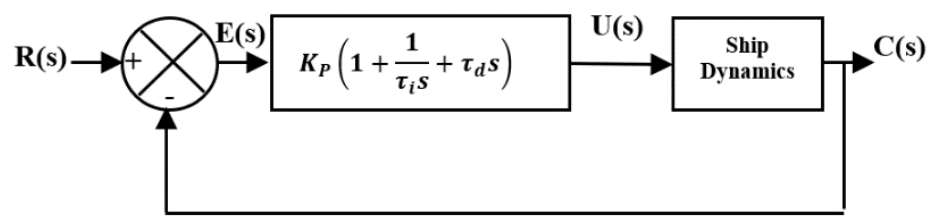

Figure 1: Block diagram of maneuvering control system [9]. 
The tuning of $\mathrm{Kp}, \mathrm{Ti}$, and Td of PID control is determined by rule as shows in Table 1 . The control gain determination of $\mathrm{Kp}, \mathrm{Ti}$ and $\mathrm{Td}$ in Fig. 1 above is obtained from the response of the control system when tested step. The response pattern will resemble the letter $\mathrm{S}$, and the gain value is obtained from the relationship in Table 1 below. The gain determination of $\mathrm{Kp}, \mathrm{Ti}$ and $\mathrm{Td}$ can be obtained from the ratio of $\mathrm{T}$ and $\mathrm{L}$, or from the ultimate gain ratio $\mathrm{Kc}$ to the oscillation period $-\mathrm{Tu}$.

Table 1: The Z-N Parameters of PID Control [8]

\begin{tabular}{|c|c|c|c|}
\hline Mode Control & Kp & Ti & Td \\
\hline P & T/L $(\mathrm{Kc} / 2)$ & $\infty$ & 0 \\
\hline PI & $0.9 \mathrm{~T} / \mathrm{L}(\mathrm{Kc} / 2.2)$ & $\mathrm{L} / 0.3(\mathrm{Tc} / 1.2)$ & 0 \\
\hline PID & $1.2 \mathrm{~T} / \mathrm{L}(\mathrm{Kc} / 1.7)$ & $2 \mathrm{~L}(\mathrm{Tc} / 2)$ & $0.5 \mathrm{~L}(\mathrm{Tu} / 8)$ \\
\hline
\end{tabular}

Notes; $\mathrm{T}$ and $\mathrm{L}$ are time parameters were achieved from step response use $\mathrm{ZN}$ Kc is gain ultimate, and $\mathrm{Tu}=$ oscillation period $[10]$.

\subsection{Maneuvering Models of Nomoto $1^{\text {st }}$}

The stability of maneuver control system can be seen from response of control system in time and frequency domain. The time domain responses must suitable to IMO criteria. In other of two responses, the maneuvering stability can be obtained from the magnitude of the Noorbin parameters - P. P is the ratio of the heading change to the rudder angle in in length vessel movement-Lpp. The maneuvering stability is indicated by the value of $\mathrm{P}>0.3$ [11]. In other of the Noorbin parameter, the yaw stability index $\left(\mathrm{C}^{\prime}\right)$ is used to the maneuvering stability. The value of $\mathrm{C}^{\prime}$ is positive indicate the yaw stability, and the negative of $C^{\prime}$ indicates the yaw instability. The yaw instability is the tendency of ships to increase of the absolute value of the yaw error. $\mathrm{P}$ and $\mathrm{C}$ 'are functions of ship dimensions, ie: Lpp, B, T, and $\mathrm{C}_{\mathrm{B}}$. The object of the ship is a SIGMA class warship, with specifications $\mathrm{L}=106 \mathrm{~m}, \mathrm{~B}=14 \mathrm{~m}, \mathrm{~T}=3.7 \mathrm{~m}$, and $\mathrm{U}=27.9$ knots. The transfer function of maneuvering model of SIGMA class war ship, in the existing design is shown of (2) below.

$$
\frac{\Psi(\mathrm{s})}{\delta_{R}(s)}=\frac{2,655671 s+0,461764}{16,030773 s^{3}+7,713468 s^{2}+s}
$$

The change of Lpp will change the ship hydrodynamic coefficient. The length of ship is variety from 1 until 1.1 of Lpp, the hydrodynamic is shown in the Table II below. The parameter changes were made to analyze the stability index. The simulation is performed for some parameter changes, with the $\mathrm{CB}$ recommendation in restriction of 0.4 to 0.6 , and the maximum of $\mathrm{L}$ is $1.1 \mathrm{Lpp}$

Table 1: The Various of Hydrodynamics Coefficient vs LPP

\begin{tabular}{|c|c|c|c|c|c|}
\hline L (x Lpp) & CB & $Y_{\dot{v}}^{\prime}$ & $Y_{\dot{r}}^{\prime}$ & $N_{\dot{v}}^{\prime}$ & $N_{\dot{r}}^{\prime}$ \\
\hline $100 \%$ & 0.4400 & -0.000088 & -0.000003 & -0.000001 & -0.000001 \\
\hline $101 \%$ & 0.4360 & -0.000092 & -0.000007 & -0.000004 & -0.000004 \\
\hline $102 \%$ & 0.4314 & -0.000181 & -0.000013 & -0.000009 & -0.000009 \\
\hline $103 \%$ & 0.4272 & -0.000268 & -0.000019 & -0.000013 & -0.000013 \\
\hline $104 \%$ & 0.4231 & -0.000352 & -0.000024 & -0.000017 & -0.000017 \\
\hline $105 \%$ & 0.4190 & -0.000434 & -0.000029 & -0.00002 & -0.000021 \\
\hline $106 \%$ & 0.4151 & -0.000513 & -0.000035 & -0.000024 & -0.000025 \\
\hline $107 \%$ & 0.4112 & -0.00059 & -0.00004 & -0.000027 & -0.000029 \\
\hline $108 \%$ & 0.4074 & -0.000665 & -0.000044 & -0.00003 & -0.000033 \\
\hline $109 \%$ & 0.4037 & -0.000748 & -0.000049 & -0.000032 & -0.000037 \\
\hline $110 \%$ & 0.4000 & -0.000809 & -0.000054 & -0.000035 & -0.00004 \\
\hline
\end{tabular}




\subsection{Design of Control PID - Zieger Nichols}

The design of PID-ZN control system of SIGMA class warships is shown in Fig. 4 below. The design of Z-N fulfilling a control stabilities in time domain. Gain of $\mathrm{Kp}, \mathrm{Ki}$ and $\mathrm{Kd}$ which give the best performance of response system are shown in the Table below. The maneuvering test is based on (IMO) resolution of MSC.137 (76) annex.6. Some criteria are: turning ability, initial turning ability, stopping ability and course keeping. When the turning test of set point $20 \mathrm{o}$ and $30 \mathrm{o}$, the value of gain PID is shown in Table III below.

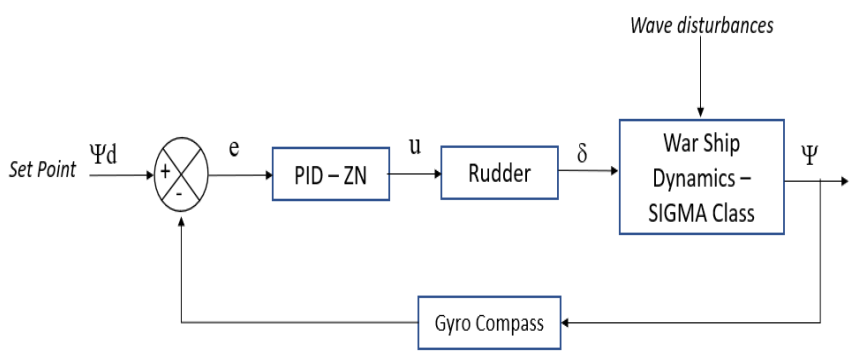

Figure 2: Block diagram of maneuvering control system in SIGMA Class war Ship.

Table 3: The Gain of PID Control in Turning Test.

\begin{tabular}{|c|c|c|c|c|c|c|}
\hline \multirow{2}{*}{ L (xLpp) } & \multicolumn{2}{|c|}{ Kp } & \multicolumn{2}{c|}{ Ki } & \multicolumn{2}{c|}{ Kd } \\
\cline { 2 - 7 } & $20^{\circ}$ & $30^{\circ}$ & $20^{\circ}$ & $30^{\circ}$ & $20^{\circ}$ & $30^{\circ}$ \\
\hline $100 \%$ & 0.05939 & 0.05760 & 0.000009 & 0.000173 & 0.14010 & 0.24980 \\
\hline $101 \%$ & 0.06444 & 0.05214 & 0.000805 & 0.000057 & 0.01946 & 0.05788 \\
\hline $102 \%$ & 0.07575 & 0.07881 & 0.000103 & 0.000025 & 0.02033 & 0.18740 \\
\hline $103 \%$ & 0.12770 & 0.07982 & 0.000035 & 0.000379 & 0.000423 & 0.03430 \\
\hline $104 \%$ & 0.06470 & 0.05820 & 0,000847 & 0.000214 & 0.02000 & 0.03270 \\
\hline $105 \%$ & 0.06790 & 0.04680 & 0,000119 & 0.000314 & 0,02000 & 0.01340 \\
\hline $106 \%$ & 0.10670 & 0.38333 & 0.001000 & 0.000135 & 0.00980 & 0.19040 \\
\hline $107 \%$ & 0.04800 & 0.03714 & 0.000394 & 0.000486 & 0.04380 & 0.31010 \\
\hline $108 \%$ & 0.09452 & 0.08798 & 0.000485 & 0.001800 & 0.35800 & 0.58640 \\
\hline $109 \%$ & 0.04466 & 0.11260 & 0.001400 & 0.000067 & 0.02350 & 0.20600 \\
\hline $110 \%$ & 0.09040 & 0.05760 & 0.000067 & 0.000173 & 0.20600 & 0.24980 \\
\hline
\end{tabular}

\section{Result and Discussion}

\subsection{Response of Control System}

The response of control system in set point of $20^{\circ}$, in various values of ship length are shown in the Graph Figure 2 below. When the set point $20^{\circ}$ yaw response of ship in length of $1 \mathrm{x} \mathrm{Lpp}$, the performance stability of response is follows: rise time of 89 seconds, settling time of 116 seconds, maximum overshoot of $20.80^{\circ}$, error steady state of $0.61 \%$ from $20^{\circ}$. Pattern of response control system in various of length of ship is similar. 
The SIGMA Class warship response for various Lpp, with maximum of length is $1.1 \mathrm{Lpp}$ are the settling time maximum of 136 seconds, maximum overshoot of $22.05^{\circ}$, steady state error maximum of $0.35 \% \times 20^{\circ}$. This response indicates that the maneuver control system give the stable perfomances.

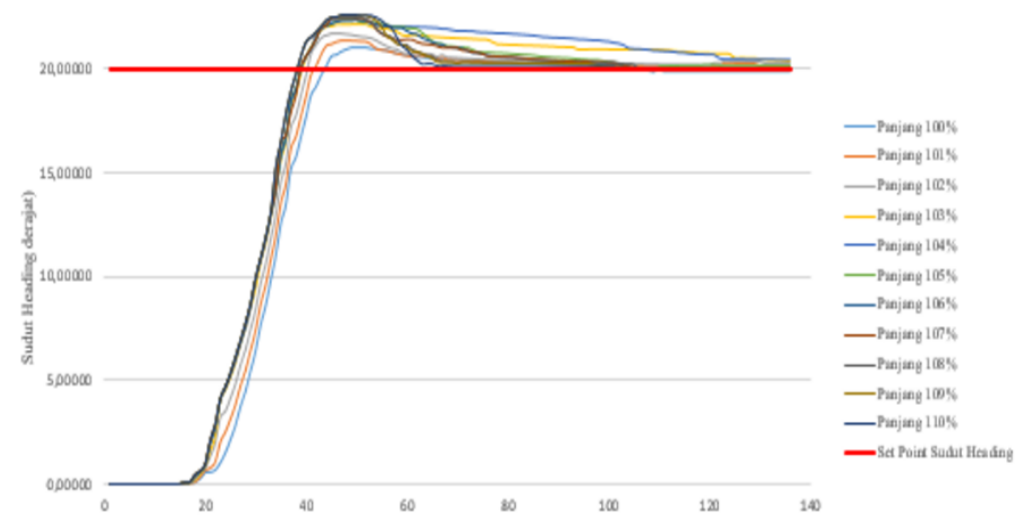

Figure 3: Response of PID control system in various of length $\mathrm{Lpp}<\mathrm{L}<1.1 \mathrm{Lpp}$. Set point $20^{\circ}$

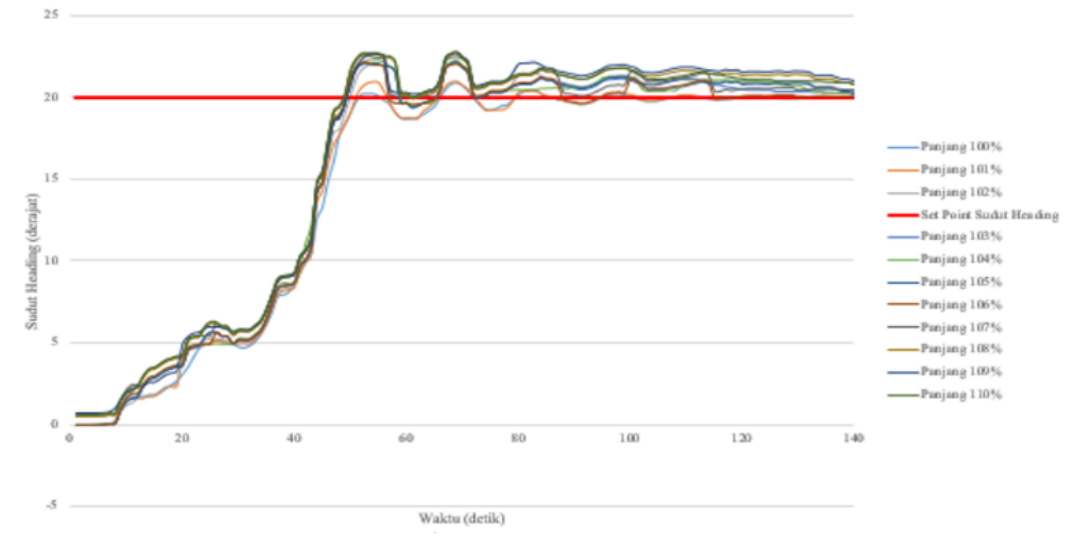

Figure 3: Response of PID control system in various of length $\mathrm{Lpp}<\mathrm{L}<1.1 \mathrm{Lpp}$. Set point 20o in wave disturbances in high state.

The test is simulated in wave disturbances. The wave transfer function models is expressed in Later Saelid, Jenssen and Balchen (1983) equations [5]. The response shows in Figure 3 above. In the figure shows the maximum overshoot never exceeds of $25^{\circ}$, and settling time maximum occurs when length of ship is $\mathrm{L}=1.1 \mathrm{Lpp}$. The ripple occurs since the control works. This is seen in the pattern on transient condition is different from when the transient pattern of response in undisturbances condition (Figure 2).

\subsection{Root Locus Analysis}

The root locus response of the system in a variety of ship length from 1.01 to $1.1 \mathrm{x}$ Lpp is shown in the Figure 4 below. The graph in Figure 4 below shows that the zero value $\mathrm{z} 1=-0.1739$, and the value of 3 poles ie, $\mathrm{p} 1=0 ; \mathrm{p} 2=-0.2406+0.0671 \mathrm{i} ; \mathrm{p} 3=-0,2406-0,0671 \mathrm{i}$. When there is changing in legth of ship in the maximum of $1.1 \mathrm{x} \mathrm{Lpp}$, the zero and pole are still located on the left of the imaginary axis. The indicates that the system is stable. The stability of ship in variety dimension can be seen on root locus plot. The poles move to the right shift of 0.014 to 0.016 units, and zero will move to the imaginary axis in 0.011 or 0.010 units. 


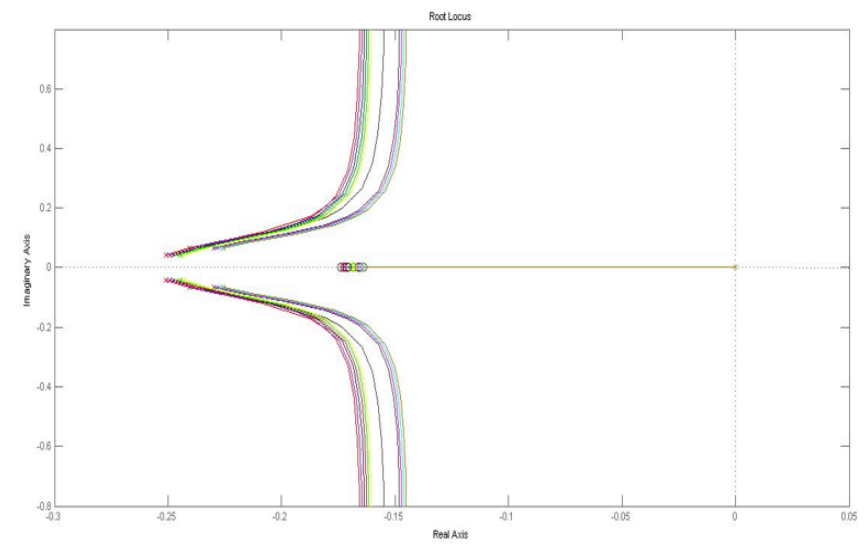

Figure 1: Root locus plot of ship dynamics in various of length $\mathrm{Lpp}<\mathrm{L}<1.1 \mathrm{Lpp}$.

The root locus test that has been done can be used to analyze the sensitivity. The sensitivity of the vessel can be obtained by pole and zero position shifting. Graphic in Fig. 3 shows the dynamics of ship maneuvering is stable. All of pole is located in lies in the left of the imaginary axis, but the greater the legth of the ship from 1.01 to $1.1 \mathrm{Lpp}$ indicates less good sensitivity. The location of pole and zero increasingly shifted to the right, and is said to lead to the maneuver instability

\subsection{Stability Index}

The yaw stability index of war ship SIGMA class in length of ship is variet in 1.01 to $1.1 \mathrm{Lpp}$, is shown in parameter of $C^{\prime}=\frac{N_{r}^{\prime}-m^{\prime} x_{g}^{\prime}}{Y_{r}^{\prime}-m^{\prime}}-\frac{N_{v}^{\prime}}{Y_{v}^{\prime}}$. The $C^{\prime}$ values are shown in Table 4 below. The value is decreased when the length of ship is increase.

Table 4: The Index Yaw Stability (C') in Various LPP.

\begin{tabular}{|c|c|}
\hline L (x Lpp) & C' $^{\prime}$ \\
\hline 1.01 & 0.305738 \\
\hline 1.02 & 0.299946 \\
\hline 1.03 & 0.298192 \\
\hline 1.04 & 0.291680 \\
\hline 1.05 & 0.287811 \\
\hline 1.06 & 0.282799 \\
\hline 1.07 & 0.279278 \\
\hline 1.08 & 0.274724 \\
\hline 1.09 & 0.269357 \\
\hline 1.10 & 0.264999 \\
\hline
\end{tabular}

\section{Conclusion}

Some of the conclusions from discussion in Chapter III are as follows:

- The root locus of maneuvering models in existing design is in the left of imaginary axis, and this is a stable model.

- In the variety of the length of ship, the response of control system is stable condition, but tend to a worst when increasing of the length ship.

- The response control system shows in fastly reach to the specified set point. 
- The yaw stability index is positive in various of ship length of 1 to $1.1 \mathrm{Lpp}$ and tend to go less value when increasing of the length of ship.

- The response of control system in set point of $20 \mathrm{o}$ and $30 \mathrm{o}$ shows the stable characteristics, and the value are not exceed of IMO criteria.

- The change of the hydrodynamic coefficients due to change of length of ship on elongated give the poor sensitivity and the performance of stability toward the less stable.

\section{Acknowledgement}

Thanks to: Ministry Research, Technology, and Higher education in funding of the research in 2014, 2015, also thanks to LPPM ITS, Laboratory of Instrumentation, Laboratory Simulation and Computer, Armada Timur Surabaya, Consorsium of Indonesia War Ship.

\section{References}

[1] J. G. Zieger, N. B. Nichols, and Rochester, "Optimum Setting for automatic Controllers,” Trans. A.S.M.E, vol. November, pp. 759-768, 1942.

[2] A. S. Aisjah, A. A. Masroeri, E. B. Djatmiko, and W. D. Aryawan, "Kontrol Logika Fuzzy Sugeno - Takagi Pada Tracking Kontrol KapaL," in Seminar Nasional Teori dan Aplikasi Teknologi Kelautan, 15 Nopember 2007, 2007, no. 1, pp. 91-107.

[3] L. Morawski, J. Pomirski, and A. Rak, "Design Of The Ship Course Control System," in International Design Conference - Design, 2006, pp. 301-308.

[4] A. S. Aisjah and S. Arifin, "Increasing Indonesia Sea Endurance By Designing Fast Patrol, Seri 1: Non Adaptif Fuzzy, " in SENTA, 2007, pp. 1-6.

[5] T. I. Fossen, Handbook Of Marine Craft Hydrodynamics And Marine Craft Hydrodynamics And. Norway: John Wiley \& Sons, 2011.

[6] A. S. Aisjah, A. A. Masroeri, M. A. Efendi, E. B. Djatmiko, D. Ariyawan, and F. A. Iskandarianto, "Fuzzy Autopilot For Ship Tracking Optimizing In Karang Jamuang - Tanjung Perak, ” In Seminar SENTA FTK 2010, 2010, pp. 111.

[7] T. I. Fossen, Guidance and Control of Ocean Vehicles - Thor I. Fossen.pdf, 1st ed. Trondheim: British Library, 1994.

[8] A. S. Aisjah, A. A. Masroeri, A. Sulisetiyono, and I. Munadhif, "Fuzzy Control System for Stability Rolling in SIGMA Class Warship,” in ISOOCEEN, 2015, no. 4, pp. 2-4.

[9] L. Morawski and J. Pomirski, "Ship track-keeping : experiments with a physical tanker model," vol. 6, pp. 763-769, 1998.

[10] S. Das, A. Chakraborty, J. K. Ray, S. Bhattacharjee, and B. Neogi, "Study on Different Tuning Approach with Incorporation of Simulation Aspect for Z-N (Ziegler-Nichols) Rules,” Int. J. Sci. Res. Publ., vol. 2, no. 8, pp. 1-5, 2012.

[11] A. S. Aisjah, "Kontrol logika fuzzy pada manuvering kapal berbasis kontrol LQG/LTR untuk membangun wahana laut tanpa awak," 2007. 